Article

\title{
Post-traumatic Stress Disorder and Social Isolation among North Korean Refugee Women in South Korea: The Moderating Role of Formal and Informal Support
}

\author{
Wonjung Ryu ${ }^{1}$ and Sun Won Park ${ }^{2, *}$ \\ 1 School of Social Welfare, Yonsei University, Seoul 03722, Korea; wjyou85@gmail.com \\ 2 Social Welfare Policy, Yonsei University Graduate School, Seoul 03722, Korea \\ * Correspondence: swsailor@hanmail.net; Tel.: +82-2-2123-2926
}

Received: 28 February 2018; Accepted: 15 April 2018; Published: 18 April 2018

\begin{abstract}
While there is abundant literature on the positive correlation between refugee post-traumatic stress disorder (PTSD) and social isolation, few studies have examined the moderating effects of formal and informal interpersonal support. This study on 154 refugee women from North Korea examines the moderating effects of formal and informal interpersonal support on the relationship between PTSD and social isolation. Data from the 2012 survey of the Ministry of Gender Equality and Family in South Korea Study on Support for Independent Living Tailored to North Korean Refugee Women Exposed to Violence were included in the present study. The study results confirmed the positive correlation between PTSD and social isolation and verified the protective effects of formal support. These findings will contribute to policy changes and early proactive interventions to reduce the social isolation of North Korean refugee women in South Korea.
\end{abstract}

Keywords: North Korean refugee women; post-traumatic stress disorder (PTSD); formal support; informal support

\section{Introduction}

Refugee resettlement and adaptation is an important issue for many countries, including the United States and the E.U. [1-3]. The year 2017 witnessed unprecedented growth in the number of migrants across the world due to war and hunger in countries such as Syria, Afghanistan, and Libya [4]. This refugee influx has aggravated social problems and conflicts in many countries [5].

The end of the Cold War eventuated the political and economic isolation of North Korea. This isolation led to massive defections beginning in the 1990s, largely due to famine and pervasive malnutrition [6]. South Korea is presently home to 31,000 North Korean refugees and approximately 1000 people arrive in South Korea each year [7]. The South Korean government has been making efforts to promote integration in the resettlement process. The South Korean constitution stipulates that the territory of the nations of South Korea and North Korea is one whole, wherein the migrants from North Korean are accepted as South Korean citizens rather than as refugees [8]. Several comprehensive measures, such as economic, medical, and educational support, for resettlement in South Korea, are in place [7] (p. 2). As a result, numerous North Korean refugees have been successfully resettled as members of South Korean society, although some have experienced difficulty. There have been instances of depression and suicide among refugees owing to severe social isolation [9].

Social isolation faced by refugees and migrants is an important factor related to survival [10]. It is often inevitable when integrating within a new society [11]. Several qualitative studies on social isolation of North Korean refugees concluded that social factors such as discrimination, economic hardship, and cultural heterogeneity can affect social isolation [12,13]. Studies in Europe and the United 
States also support this conclusion [14,15]. Although these factors may lead to social isolation, refugees, unlike migrants, are more likely to be affected by emotional problems, as they often experience serious trauma before entry [16]. As a result, post-traumatic stress disorder (PTSD) among refugees poses as a serious risk factor that threatens successful resettlement [17-19].

Various support systems are worth consideration in this regard. Adequate social support may prevent social isolation among refugees who frequently suffer from PSTD [20]. Such findings are consistent with Cohen and Will's [21] Stress Buffering Model, which explains that supportive formal and informal social systems can help individuals deal with stressful events such as conflict in a relationship and also prevent stress-related psychological symptoms from deepening. According to this theory, providing both informal and formal support to refugees in psychological crises is essential [22]. Some research shows that the negative consequences of stress may be overcome via strong informal social support [23,24]. However, refugees who were severely affected by PTSD find it difficult to form decent informal networks. This can occur for several reasons. For example, the social support erosion model [25-27] suggests that early symptoms of PTSD may result in broken-off relationships or result in the maintenance and formation of only superficial relationships. Valuable social resources can be useless if a refugee is reluctant or unwilling to engage with the social network [28]. These theories stress the importance of developing a support system that corresponds to individual needs and circumstances.

This study investigates the correlation between PTSD experienced by North Korean refugees and their social isolation, and examines the moderating influence of protective factors of formal and informal social support systems. About two-thirds of North Korean refugees are women [7] (p. 2), and previous studies show that PTSD and emotional crises present differently between males and females $[29,30]$. Hence, the present study examines only North Korean refugee women.

\section{Background: Traumatic Events and PTSD among North Korean Refugee Women}

People in North Korea experience massive trauma before fleeing to South Korea [31]. The communist regime of North Korea has for more than half a century exercised absolute internal control and enforced isolation policies on its people [32], resulting in human rights violations, extra-judicial executions, forced disappearances, torture, famine as an instrument of political control, internment in political prisons that have been compared to the concentration camps of the Nazis, and other violations too numerous and heinous to list [33,34]. North Korea is characterised by a pervasive patriarchal family environment [35], leading to an oppressive domestic environment typified by violent husbands and fathers [36]. The North Korean regime uses patriarchal and neo-Confucian values as a means to secure its own legitimacy and success [37]. North Korean refugee women are thus vulnerable to PTSD because of victimization by the state and in private life inside North Korea. Such victimization may involve witnessing death, beatings, surveillance, life-threatening food shortages, and numerous traumatic events such as domestic violence. To date, there is lack of research on PTSD in North Korean society. A comparison, however, with Sudan, which has suffered civil war and dictatorship, shows that $48 \%$ of the 3323 subjects surveyed in 2004 showed symptoms of PTSD [38].

Fleeing from North Korea can be traumatic and is sometimes deadly for refugees. The escape, even when successful, leads to instability among refugees ranging from few months to over 5 years depending on whether they attempt to stay in China. The refugees living along the Chinese border of North Korea are not allowed to hold refugee status in China and are forcibly repatriated to North Korea if detected by authorities [39]. Leaving the North Korean state without permission is considered treason [40]. Hence, those forcibly repatriated are subject to torture, sexual assault, forced abortion, and infanticide by border guards, malnourishment and internment in disease ridden labour camps, internment in political prisons, and summary execution [41]. Therefore, North Korean refugees are under constant fear of being arrested, of facing forced marriage via human traffickers, and of violence and/or death. A study of 170 North Korean refugees living in China reported that they each 
experienced an average of 12 different traumas, such as the 'unnatural death of family or friend' and 'being close to death', and 56\% of the respondents showed at least one symptom of PTSD [42].

Such serious traumatic events faced by North Korean refugees have led to high prevalence of PTSD before entry into South Korea (nearly $25-50 \%$ among those surveyed in South Korea $[43,44]$ ). Moreover, North Korean refugee women show two or more times more severe PTSD symptoms than men [45], probably because refugee women are more likely to be traumatised due to widespread sexual violence. Even 10 years after resettlement, $86 \%$ of the refugees surveyed are reported to show significant PTSD symptoms [46].

\section{Literature Review}

\subsection{Relationship between PTSD and Social Isolation}

PTSD is a major cause of social isolation [47]. Risk factors for refugees or migrants regarding social isolation include problems in the resettlement process such as social discrimination [48] and economic deprivation [49]. Unlike migrants, however, refugees are likely to face emotional crises such as unresolved PTSD [50,51]. Although North Korean refugee women can lead better lives in South Korea due to stable jobs and improved economic status, these women may suffer from psychological conditions such as PTSD. The most common responses to PTSD symptoms are interpersonal avoidance, self-critical thinking [52], and emotional adjustment problems [53,54]. These symptoms affect North Korean refugees' relational and emotional ability to settle into South Korean society, resulting in social isolation. PTSD symptoms lead to symptoms of avoidance [18] (p. 2) or fear [19] (p. 2), and reduced trust in others, which can lead to dysfunctional choices in interpersonal relationships [55]. Hofmann, Litz, and Weathers [47] (p. 3) reported that soldiers with post-war PTSD experienced numerous interpersonal conflicts and isolation issues in the process of reintegration into their family and society. Self-critical thinking can result in extremely passive attitudes in primary relationships, because the individual feels helpless and inferior to others [56,57]. Emotional regulation is another important risk factor for relational isolation [58]. As noted above, symptoms of PTSD can significantly exacerbate the isolation of North Korean refugees.

\subsection{Moderation Effect of Formal and Informal Social Support}

Social support is an important protective factor that can help reduce the social isolation of refugees suffering from emotional crises $[20,21]$ (p. 2). Typically, social support not only alleviates stress but also improves the individual's coping ability [59] and provides psychological compensation for social conflicts or lack of relationships [60]. Neurobiological factors corroborate these results. Individuals suffering from PTSD or isolation exhibit a high level of the oxidative stress hormone called cortisol [61]. Social support plays a significant role in lowering cortisol levels [62], and it can thus play a role in mitigating social isolation by improving psychological stability [16] (p. 2) among refugees with symptoms of PTSD. Such support may be particularly more important for refugee women than for refugee men. For example, a study of victims of violence reported that satisfaction with social support can positively affect their mental health, and the effect is higher for women than in men [63]. Previous studies on social support provide an integrated view of the environmental support system for individuals. As North Korean refugees are generally viewed as a group that hesitates to forge new relationships South Korean society, the social support system is limited, and its influence may vary.

This study examines the formal support extended by the support staff to North Korean refugees and the informal support extended by their neighbours. In the context of language barriers and cultural differences, as well as lack of economic and cultural information, formal support becomes crucial for North Korean refugee women. Formal support is limited to providing information alone and does not provide active psychological support [64]. However, previous research suggests informal support plays a complementary role in overcoming the limitations of formal support [65], and numerous refugee women rely on local community support to offset the limitations of formal support [66]. A few 
studies have reported that formal support was highly effective [67]. On the other hand, some studies reported that informal support is more effective than formal support in stressful situations $[68,69]$. These contradictory studies suggest that the usefulness of social support may vary by purpose and group [28] (p. 2). Therefore, it is necessary to ascertain the roles played by both formal and informal support in the relationship between PTSD and social isolation among North Korean refugees.

\subsection{Covariates}

Various causes other than PTSD may also lead to social isolation among North Korean refugee women. Refugees may find resettling in a new society difficult due to limitation of occupational opportunities [70]. Moreover, language and cultural differences between the two Koreas [71] may be important factors that aggravate social isolation. North Korean refugees consider economic independence as the most important condition for living in South Korean society [72]. However, their greatest desire is to engage in meaningful occupational activity in South Korean society. Many North Korean refugees experience difficulty in finding a job, and the average length of employment is only 25.2 months', even when employment is found [73]. Insecurity in employment may result from workplace discrimination and prejudice, as well as a lack of education or adaptive orientation to social interactions [74].

In addition to employment issues, North Korean refugees face language and cultural barriers [71] (p. 4). In the past 50 years, the two Koreas have seen significant changes in their respective cultures and languages. Differences in vocabulary, intonation, grammar, and neologisms have widened [75]. For example, in South Korea, mobile phones, ice cream, and knocking are used as direct loanwords, while North Korea translates these into Korean words. Therefore, although North Korean refugees can manage basic communication in South Korea, they have trouble engaging in meaningful conversations and understanding the context [76]. In addition, the distinct North Korean dialect and intonation reveals the origin of the speaker to members of South Korean society and may result in discrimination [77]. Furthermore, age [78], length of sojourn in South Korea [79], and income are important factors in determining social isolation [80].

\section{Methodology}

\subsection{Sample and Procedures}

For the purpose of this study, data were collected from 154 North Korean refugee women living in South Korea. A 2012 study by the Ministry of Gender Equality and Family in South Korea titled 'A Study on Support Plans for Independent Living Tailored to North Korean Refugee Women who are Victims to Violence' formed the basis of secondary data. Primary data was collected through a survey conducted from April to June 2012. Despite limitation of generalisability, the snowball sampling method was used. Residential information of North Korean refugees remains strictly confidential. Moreover, most North Korean refugees did not want to reveal their identity because of threat of terrorism or social discrimination. Therefore, several studies on North Korean refugees have relied on the snowball sampling method instead of unrealistic random sampling. In this study, experts with excellent understanding of North Korean refugees were introduced to each family by visiting them. Survey participants were remunerated 10,000 Korean Won (\$10) for their participation in the study.

The sample size required was calculated by power analysis using $G$ * power 3.1 [81]. The effective size was assumed to be 0.15 , at a significance level of $0.05 ; 0.80$ was the power level used, and the number of predictors was 8 . Consequently, the reliable sample size in this study was determined to be approximately 109 [82], which confirmed that the sample size of 156 subjects in this study was appropriate.

Table 1 shows the demographic characteristics and the main variables of the subjects. The age range of the subjects was 21-77 years $(\mathrm{M}=42.78, \mathrm{SD}=9.23)$, and the resettlement duration in South Korea was $2-16$ years $(\mathrm{M}=6.49, \mathrm{SD}=2.72)$. About $4.5 \%$ of the subjects had no income, and the 
average monthly household income of $35.7 \%$ was at the low level of $\$ 1000$ or less. The mean value of social isolation, which is a dependent variable in this study, was reported to be $2.09(\mathrm{SD}=0.39)$, corresponding to a moderate social isolation score. Of the subjects, $59.7 \%$ had been diagnosed with PTSD, and over half of the subjects showed PTSD symptoms. Finally, it was seen that North Korean refugee women better appreciated formal support $(\mathrm{M}=2.56, \mathrm{SD}=0.60)$ than informal $(\mathrm{M}=2.58$, $\mathrm{SD}=0.57)$.

Table 1. Sample Characteristics $(\mathrm{N}=154)$.

\begin{tabular}{|c|c|c|c|c|}
\hline \multicolumn{2}{|c|}{ Variable } & N (\%) & $M(S D) *$ & Range \\
\hline \multicolumn{2}{|l|}{ Age } & - & $42.78(9.23)$ & $21-77$ \\
\hline \multicolumn{2}{|c|}{ Duration in South Korea } & - & $6.49(2.27)$ & $2-16$ \\
\hline \multirow{5}{*}{ Monthly Income } & No income & $7(4.5)$ & - & - \\
\hline & Under $\$ 1000$ & $55(35.7)$ & - & - \\
\hline & $\$ 1000-\$ 1999$ & $45(29.2)$ & & \\
\hline & $\$ 2000-\$ 2999$ & $29(18.8)$ & - & - \\
\hline & Over $\$ 3000$ & $18(11.7)$ & - & - \\
\hline \multirow{2}{*}{ Employment \& Work difficulties } & Single & $36(23.2)$ & - & - \\
\hline & Married & $118(76.8)$ & - & - \\
\hline \multirow{4}{*}{ Language \& Culture difficulties } & Suicidal ideation & $61(39.6)$ & & - \\
\hline & Suicidal plan & $48(31.2)$ & - & - \\
\hline & Suicidal attempt & $26(16.9)$ & - & - \\
\hline & Any suicidal risk & $69(44.8)$ & - & - \\
\hline \multicolumn{2}{|c|}{ Social isolation } & - & $2.09(0.39)$ & - \\
\hline \multicolumn{2}{|c|}{ PTSD } & $89(59.7 \%)$ & - & \\
\hline \multicolumn{2}{|c|}{ Formal support } & - & $2.56(0.60)$ & - \\
\hline \multicolumn{2}{|c|}{ Informal support } & - & $2.58(0.57)$ & - \\
\hline
\end{tabular}

${ }^{*}$ Mean scores of continuous variables before being cantered to 0 .

\subsection{Measures}

\subsubsection{Social Isolation}

Social isolation is adopted from the scale used in a study by Lee [83], who adapted and translated the UCLA Social Loneliness (UCLA-SL) Scale. This scale was developed by Russell [84] for use in Korean subjects. The UCLA-SL has been used in many studies to measure social isolation. The scale includes a total of 10 items. Six items are as follows: 'I am no longer close to anyone', 'I often feel isolated from others', 'There is no one I can turn to when I am in trouble', 'People are around me but not with me', 'I feel left out', and 'My social relationships are superficial'. Four reverse items are as follows: 'I am an outgoing person', 'I can find companionship when I want it', 'I feel in tune with the people around $\mathrm{me}^{\prime}$, and 'There are people I can talk to'. Likert scale was used to measure: 1 (never), 2 (rarely), 3 (sometimes), and 4 (often). Mean values were calculated after recoding reverse items for the final analysis (Table 2). The Cronbach's alpha of this scale was 0.802 . 
Table 2. Multivariable regression of social isolation $(\mathrm{N}=154)$.

\begin{tabular}{|c|c|c|c|c|}
\hline \multirow{2}{*}{ Variables } & \multicolumn{4}{|c|}{ Model } \\
\hline & B & SE & B & $95 \% \mathrm{CI}$ \\
\hline Constant & 1.994 & 0.225 & & {$[1.55,2.44]$} \\
\hline Age & -0.009 & 0.034 & -0.019 & {$[-0.08,0.06]$} \\
\hline Duration in South Korea & 0.097 & 0.050 & 0.148 & {$[0.00,0.20]$} \\
\hline Income & 0.000 & 0.000 & -0.032 & {$[0.00,0.00]$} \\
\hline Employment \& work difficulties & 0.107 & 0.048 & $0.182 *$ & {$[0.01,0.20]$} \\
\hline Language \& culture difficulties & 0.042 & 0.021 & $0.171 *$ & {$[0.00,0.08]$} \\
\hline PTSD & 0.199 & 0.050 & $0.296^{* * *}$ & {$[0.10,0.30]$} \\
\hline Formal support & -0.046 & 0.053 & -0.070 & {$[-0.15,0.06]$} \\
\hline Informal support & -0.187 & 0.057 & $-0.277^{* *}$ & {$[-0.30,-0.07]$} \\
\hline PTSD X Formal support & -0.317 & 0.097 & $-0.258^{* *}$ & {$[-0.51,-0.13]$} \\
\hline PTSD X Informal support & 0.174 & 0.090 & 0.158 & {$[0.00,0.35]$} \\
\hline$R^{2}$ & & & 0.279 & \\
\hline Adjusted $R^{2}$ & & & $0.286 * *$ & \\
\hline F & & & $6.567^{* * *}$ & \\
\hline
\end{tabular}

\subsubsection{PTSD}

The PTSD diagnostic scale of the Diagnostic and Statistical Manual of Mental Disorders-IV (DSM-IV) was used in this study. This scale consists of 19 items in total, including five for re-experiencing symptoms after the trauma, seven for symptoms of avoidance and paralysis, five for symptoms of hyper arousal, one for dysfunction lasting 1 month or more, and one item for dysfunction-related difficulties in daily life. The rating scale consists of 'Never (0)', 'Insignificant (1)', and 'Severe (2)', and answers were obtained as 'less than one year after entry' and 'past one week'. In this study, based on temporal causality with dependent variables, data of 'past one week' were used. As shown in Table 2, the mean value was used for the final analysis. The method of diagnosis specified in DSM-IV was used in Table 1, which shows the presence of PTSD symptoms. The Cronbach's alpha of this scale was 0.973 .

\subsubsection{Formal Support}

This study adopted the social relationship scale used in the 2012 Ministry of Gender Equality and Family survey in South Korea to measure formal support for North Korean refugee women. This scale is adapted for the characteristics of North Korean refugees. It measures the social relations that North Korean defectors have with special people and staff. In terms of formal support, only four items on the relationship with special people and staff in charge for North Korean refugees were used from the above scales. However, since Cronbach's alpha for the four items was very low at 0.677 , only three items were used for the analysis, excluding the one with the lowest reliability. The excluded item is 'I can talk to the special people and staff for North Korean refugees about my problems.' The final analysis included the following three items: 'The special people and staff for North Korean refugees

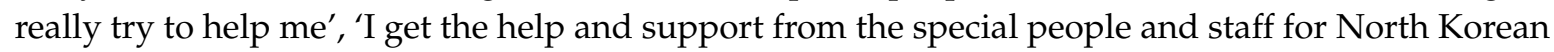
refugees in South Korea', and 'Special people and staff for North Korean refugees are willing to help you making my own decisions'. The average value was included in the final analysis. The rating scale consists of 'Not at all', 'Do not agree', 'Agree', and 'Highly agree'. The Cronbach's alpha of this scale was 0.859 .

\subsubsection{Informal Support}

In this study, we used the neighbourhood scale in the 2012 Ministry of Gender Equality and Family Survey to measure informal support for North Korean refugees. The scale includes four questions: 'Do you have friendly relationships with your neighbours?', 'Are there local residents to help you when your family faces an important problem?', 'Do you think your neighbours trust each 
other?', and 'Do you think your local residents are willing to help their neighbours?' The average value was used for the final analysis, and the rating scale consisted of 'Not at all', 'Do not agree', 'Agree', and 'Highly agree'. The Cronbach's alpha of this scale was 0.861 .

\subsubsection{Covariates}

From previous studies, the present study used control variables for the factors affecting social isolation in addition to the main variables. Demographic characteristics included age, duration of resettlement, and income as control variables, in addition to 'work-related problems' and 'difficulties in language and cultural adjustment' as factors of social isolation faced during the process of settling in South Korean society.

Age and resettlement period were calculated based on the time of the survey (2012 years). The income level is taken as the monthly average, considering the three items 'subject's income', 'husband's income', and 'other family members' income'. The sample characteristics and final analysis (Tables 1 and 2) were converted to US dollars and categorised into five income levels (no income, under \$1000, \$1000-\$1999, \$2000-\$2999, and over \$3000). 'Employment \& Work difficulties 'and 'Language \& Culture difficulties' were measured using the social difficulty scale for North Korean refugees by Joen, Yoon, \& Um was developed [85]. 'Employment \& Work difficulties 'scale consisted of two questions on understanding problems of 'employment' and 'work life (adaptation)', and the final analysis used the mean value. Regarding 'Language \& Culture difficulties', two questions on 'language problems' and 'differences in culture, ways of thinking and lifestyle' were used, and the mean value was used for the final analyses. The rating scale consisted of 'not difficult at all', 'not difficult', 'difficult', and 'extremely difficult'.

\subsection{Data Analysis Plan}

In this study, data were analysed using SPSS 24.0. Analyses were conducted in three stages. First, frequency analysis and descriptive statistics were conducted to identify the demographic characteristics, as well as PTSD status, social isolation, and formal and informal support. Control variables included age, resettlement duration, average monthly household income, employment and work difficulties, and language and culture difficulties. Second, to examine the relationship between PTSD and social isolation for North Korean refugee women, as well as to study the moderating effect of formal and informal support, multiple regression analysis was conducted using interaction terms.

Multi-collinearity was examined for every regression analysis, and there was no problematic multi-collinearity in the analyses; the highest VIF was 1.685, and the lowest tolerance was 0.605.

\section{Results}

Table 2 presents the results of the multivariable regression models. This model verified the relationship between PTSD and social isolation, as well as the moderating effects of formal and informal supports. The variables used in this study were analysed as continuous variables after mean centering. The explanatory power of the model was $28.6 \%$. Moreover, the results showed that PTSD and social isolation had a positive correlation $(\beta=0.96, p<0.001)$ and that informal support showed a negative correlation $(\beta=-0.277, p<0.01)$. The results indicate that social isolation was high in case of higher symptoms of PTSD and low informal support. In the validation of the moderating effect, formal support was verified as a factor controlling PTSD and social isolation $(\beta=-0.258, p<0.01)$. This result verified that formal support influences the relationship between PTSD and social isolation. For the control variables, the greater the difficulty at work $(\beta=-0.24, p<0.05)$, and in language and culture $(\beta=-0.24, p<0.05)$, the greater the social isolation.

Figure 1 shows a graph to determine whether formal support is statistically significant in the influence of PTSD on social isolation based on the regression analysis above. Consequently, social isolation increased as PTSD increased, confirming the positive correlation, and the inclination was less 
steep in the group with higher formal support than it was in the group with lower formal support. The results indicate that formal support plays a role as a control variable in protecting the relationship between social isolation and PTSD.

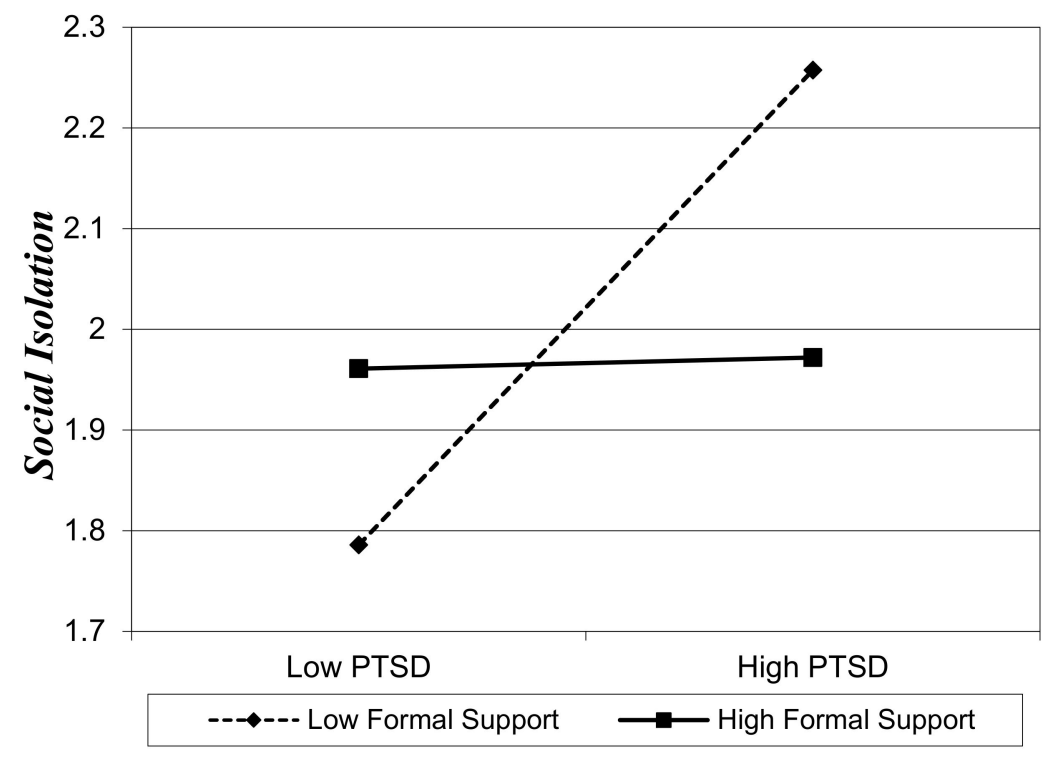

Figure 1. Moderation effect of formal support on the association between PTSD and social isolation. Range of PTSD and formal support are from (mean $-1 S D)$ to (mean $+1 S D)$. These variables before being centered to 0 .

\section{Discussion}

Studies, so far, on the social isolation of refugees have focused on the problems arising from migration. However, because refugees characteristically have a high prevalence of PTSD resulting from serious trauma, it may be that PTSD interferes with the formation of social relations and plays an important role in exacerbating isolation; this is supported by the relationship between PTSD and isolation verified by this study. First, 59.7\% of subjects showed PTSD symptoms similar to the rates of PTSD symptoms among North Korean refugee women surveyed in other studies [86]. Furthermore, PTSD symptoms and isolation showed a positive correlation. In addition, work-related problems experienced in South Korean society as well, as difficulties with language and cultural adaptation, were also shown to be risk factors for isolation. Comprehensively, the results suggest that multidimensional intervention is required to alleviate social isolation in North Korean refugee women. At present, worldwide, initial intensive assistance is being provided for early resettlement of refugees. The South Korean government also provides economic, housing, medical, and employment support services to help North Korean refugees settle in society [7] (p. 2). Refugees receive information to help them understand South Korean society, as well as educational services during the first 14 weeks of entry (12 weeks in resettlement support facilities called 'Hanawon', 2 weeks in residence). However, this is too short a duration to understand South Korean society and to alleviate isolation. The time to gain emotional stability and promote health is only $50 \mathrm{~h}$ of 392 [87]. The relationship between PTSD and isolation examined in this study is not a temporary phenomenon. Therefore, various long-term interventions such as emotion therapy, language and cultural education, and vocational education should be undertaken, rather than focusing on the initial education alone.

The roles of formal support and informal support verified in this study are also important. In this study, informal support was directly related to social isolation, although it was not verified as a factor that could control PTSD and social isolation. By contrast, formal support was not directly related to social isolation, but it was verified as a factor controlling PTSD and social isolation. The results that previously described it have some implications for the roles of formal and informal support. 
First, informal support, which is directly related to daily life, is important, because it involves a closer relationship than formal support. These results support the findings that informal support is crucial for refugee women to settle into a new society. Residents in the neighbourhoods [88] who have daily contact with refugee women can be an important resource for alleviating refugees' social isolation. While refugee women can use these relationships and activities to create a measure of balance and gain greater autonomy in their lives, they are also the sites for waging battles over their past and present identities [89]. Thus, it is necessary to link and activate local communities with refugee women so that these women can form positive neighbourhood identities within South Korean society. Second, high-quality service is essential for North Korean refugee women suffering such serious emotional crises as PTSD. The study results verified that formal support influences the relationship between PTSD and social isolation. This result could provide important intervention directions for North Korean refugees. It is thus necessary to provide pre-screening and information before they face critical maladjustment such as isolation due to emotional crisis. North Korean refugees may not have sufficient understanding of the health and counselling systems available in South Korean society, as well as the importance of health and counselling during initial resettlement. However, as mentioned above, the counselling service offered immediately upon arrival in South Korea is qualitatively and quantitatively insufficient. It is necessary to increase professional counselling hours at Hanawon and other interventions in the case of refugees identified as having problems through pre-screening. Furthermore, it is necessary to consider Korean embassies in third, transit countries such as China and Thailand. Most North Korean refugees stay in embassies of third countries for a short duration before entering South Korea [39] (p. 2). As numerous studies suggest the importance of early intensive interventions in PTSD [90,91], it is necessary to amend policies in which the Korean Embassy in the third countries would not only protect the refugees but would also offer expert crisis interventions to refugees exposed to traumatic events. In addition, there is a need to strengthen the quantitative and qualitative formal support systems provided after resettlement. Although refugee women have some social capital, they do not have a strong connection with social capital [92]. Therefore, the role of the public workers that provides formal support is very important. Currently, protection officers are deployed for regional resettlement support, administrative support, and the personal protection of North Korean refugees. Protection officers are highly valued as total formal supporters, who are responsible for coordinating various services such as government subsidies, housing, and medical support services, as well as security services, for North Korean refugees. However, the number of protection officers is insufficient to handle 31,000 North Korean refugees. Currently, there are 800 protection officers in total; in other words, one officer for every 30 refugees, on average [93]. Moreover, some protection officers lack expertise. Thus, improvement in the number and quality of the current protection officers is warranted.

\section{Limitations and Suggestions for Future Research}

There are some limitations to this study. First, the study results cannot be generalised, because the data were collected through snowball sampling. It is unclear whether its results accurately represent the entire population. The research on the North Korean refugee group, for which the residence and personal information are thoroughly confidential, inevitably relies on snowball sampling. Snowball sampling, while effective in estimating a hidden population, did not fully reveal this population's problems despite its exposure to serious crises. For more accurate research results, we suggest unbiased estimates through respondent-driven sampling.

Second, the scope of the support system examined was limited. The formal support system used in this study corresponds to the support for North Korean refugees by staff, and informal support corresponds to neighbourhood relationships. Although there could be various support systems through which North Korean refugees create relationships, there are limitations to characterising the full range of variety in these research data. The two representative support systems that form the 
closest relationship with North Korean refugees were considered, however, and their relevance was based on previous studies.

Third, in the neighbor relationship scale for informal support used in this study, it was not easy to accurately determine whether the neighbor was a North Korean refugee or a native South Korean resident. In the case of refugees, the neighbor could play different roles even in the same situation, depending on whether the neighbor is a North Korean refugee or a South Korean. Therefore, further study is required to explore in detail the determinants of informal support.

Fourth, future studies must examine how subjective satisfaction with social support differs from the quantity and frequency of social contacts. Many existing studies [94-96] propose that an individual's perception of social networks can play an important role in determining the degree to which individuals are willing to find and utilize necessary resources. Such studies can provide important guidance for intervention with North Korean refugees lacking or disoriented in social networks.

\section{Conclusions}

The current worldwide increase in population migration has repercussions on the social discourse surrounding refugee issues in host countries [97-99]. Some countries have strictly limited the recognition of refugee status or have reduced migration inflow because of social cost, increased crime rates, or social conflicts. However, aside from humanitarian concerns and costs, the influx of refugees could also be positive with regard to securing an additional workforce from other countries that are suffering from war and hunger and allowing host countries to develop new sources of social improvement [98-101]. Identifying causes of refugee social isolation and early intervention methods is essential, because preventing isolation in a new society is an important determinant of a success social integration. From this viewpoint, the relationship between PTSD and social isolation, the protective effect of formal support, and the main effect of informal support examined in this study offer valuable directions for interventions to alleviate the social isolation of refugees.

Author Contributions: All authors contributed equally to all aspects of the research reported in this paper.

Conflicts of Interest: The authors declare no potential conflicts of interest with respect to the research, authorship and/or publication of this article.

\section{References}

1. Al-Husban, M.; Adams, C. Sustainable Refugee Migration: A Rethink towards a Positive Capability Approach. Sustainability 2016, 8, 451. [CrossRef]

2. Pachocka, M. The Twin Migration and Refugee Crises in Europe: Examining the OECD's Contribution to the Debate. In Rocznik Instytutu Europy Środkowo-Wschodniej, 14(4 Re-thinking the OECD's Role in Global Governance: Members, Policies, Influence); 2016; pp. 71-99. Available online: http://yadda.icm.edu.pl/yadda/ element/bwmeta1.element.ekon-element-000171439566 (accessed on 1 October 2016).

3. Crush, J.; Tevera, D.S. (Eds.) Zimbabwe's Exodus: Crisis, Migration, Survival; Southern African Migration Programme; African Books Collective: Oxford, UK, 2010.

4. Bris, P.; Bendito, F. Lessons Learned from the Failed Spanish Refugee System: For the Recovery of Sustainable Public Policies. Sustainability 2017, 9, 1446.

5. Crush, J. The dark side of democracy: Migration, xenophobia and human rights in South Africa. Int. Migr. 2001, 38, 103-133. [CrossRef]

6. Um, M.Y.; Chi, I.; Kim, H.J.; Palinkas, L.A.; Kim, J.Y. Correlates of depressive symptoms among North Korean refugees adapting to South Korean society: The moderating role of perceived discrimination. Soc. Sci. Med. 2015, 131, 107-113. [CrossRef] [PubMed]

7. Ministry of Unification. Statistic for North Korean Refugees in South Korea. Available online: http://www. unikorea.go.kr/unikorea/business/NKDefectorsPolicy/status/lately/ (accessed on 1 March 2018).

8. Lee, D.Y. The Task of Establishing the 'Constitutional Identity' and the Constitutional Status of North Korean Defectors. Justice 2013, 136, 27-63. 
9. The New York Times. Life in South hard for North Koreans. Available online: http:/ / www.nytimes.com/ 2000/04/24/world/life-in-south-hard-for-north-koreans.html (accessed on 24 April 2010).

10. Baumeister, R.F.; Leary, M.R. The need to belong: Desire for interpersonal attachments as a fundamental human motivation. Psychol. Bull. 1995, 117, 497-529. [CrossRef] [PubMed]

11. Pittaway, E.; Muli, C.; Shteir, S. 'I have a voice-Hear me!' Findings of an Australian Study Examining the Resettlement and Integration Experience of Refugees and Migrants from the Horn of Africa in Australia. Available online: https://refuge.journals.yorku.ca/index.php/refuge/article/view/32084 (accessed on 17 April 2018).

12. Jeon, B.H.; Kim, M.D.; Hong, S.C.; Kim, N.R.; Lee, C.I.; Kwak, Y.S.; Park, J.H.; Chung, J.; Chong, H.; Jwa, E.K. Prevalence and correlates of depressive symptoms among North Korean defectors living in South Korea for more than one year. Psychiatry Investig. 2009, 6, 122-130. [CrossRef] [PubMed]

13. Chung, B.H. Between defector and migrant: Identities and strategies of North Koreans in South Korea. Korean Stud. 2008, 32, 1-27. [CrossRef]

14. Hynie, M. The Social Determinants of Refugee Mental Health in the Post-Migration Context: A Critical Review. Can. J. Psychiatry 2017. [CrossRef] [PubMed]

15. Stewart, M.; Kushner, K.E.; Dennis, C.; Kariwo, M.; Letourneau, N.; Makumbe, K.; Makwarimba, E.; Shizha, E. Social support needs of Sudanese and Zimbabwean refugee new parents in Canada. Int. J. Migr. Health Soc. Care 2017, 13, 234-252. [CrossRef]

16. Schweitzer, R.; Melville, F.; Steel, Z.; Lacherez, P. Trauma, Post-Migration Living Difficulties, and Social Support as Predictors of Psychological Adjustment in Resettled Sudanese Refugees. Aust. N. Z. J. Psychiatry 2006, 40, 179-187. [CrossRef] [PubMed]

17. Ai, A.L.; Peterson, C.; Ubelhor, D. War-related trauma and symptoms of posttraumatic stress disorder among adult Kosovar refugees. J. Trauma. Stress 2002, 15, 157-160. [CrossRef] [PubMed]

18. Sautter, F.J.; Glynn, S.M.; Thompson, K.E.; Franklin, L.; Han, X. A couple-based approach to the reduction of PTSD avoidance symptoms: Preliminary findings. J. Marital Fam. Ther. 2009, 35, 343-349. [CrossRef] [PubMed]

19. Zoellner, L.A.; Pruitt, L.D.; Farach, F.J.; Jun, J.J. Understanding heterogeneity in PTSD: Fear, dysphoria, and distress. Depress. Anxiety 2014, 31, 97-106. [CrossRef] [PubMed]

20. Al-Sheikh, N.A.M.; Thabet, A.A.M. Post-Traumatic Stress Disorder due to War Trauma, Social and Family Support among Adolescent in the Gaza Strip. J. Nursing Health Sci. 2017, 3, 10.

21. Cohen, S.; Wills, T.A. Stress, social support, and the buffering hypothesis. Psychol. Bull. 1985, 98, 310. [CrossRef] [PubMed]

22. Chan, N.; Anstey, K.J.; Windsor, T.D.; Luszcz, M.A. Disability and depressive symptoms in later life: The stress-buffering role of informal and formal support. Gerontology 2011, 57, 180-189. [CrossRef] [PubMed]

23. Benson, P.R. The impact of child symptom severity on depressed mood among parents of children with ASD: The mediating role of stress proliferation. J. Autism Dev. Disord. 2006, 36, 685-695. [CrossRef] [PubMed]

24. Ozbay, F.; Johnson, D.C.; Dimoulas, E.; Morgan, C.A., III; Charney, D.; Southwick, S. Social support and resilience to stress: From neurobiology to clinical practice. Psychiatry (Edgmont) 2007, 4, 35-40. [PubMed]

25. King, D.W.; Taft, C.; King, L.A.; Hammond, C.; Stone, E.R. Directionality of the association between social support and posttraumatic stress disorder: A longitudinal investigation. J. Appl. Soc. Psychol. 2006, 36, 2980-2992. [CrossRef]

26. Laffaye, C.; Cavella, S.; Drescher, K.; Rosen, C. Relationships among PTSD symptoms, social support, and support source in veterans with chronic PTSD. J. Trauma. Stress 2008, 21, 394-401. [CrossRef] [PubMed]

27. Clapp, J.D.; Beck, J.G. Understanding the relationship between PTSD and social support: The role of negative network orientation. Behav. Res. Ther. 2009, 47, 237-244. [CrossRef] [PubMed]

28. Dubos, R. Social Capital: Theory and Research; Routledge: London, UK, 2017.

29. Noh, J.W.; Park, H.; Kwon, Y.D.; Kim, I.H.; Lee, Y.H.; Kim, Y.J.; Kim, S.G. Gender Differences in Suicidal Ideation and Related Factors among North Korean Refugees in South Korea. Psychiatry Investig. 2017, 14, 762-769. [CrossRef] [PubMed]

30. Van Loon, L.; Van de Ven, M.O.; Van Doesum, K.; Hosman, C.M.; Witteman, C.L. Parentification, stress, and problem behavior of adolescents who have a parent with mental health problems. Fam. Process 2017, 56, 141-153. [CrossRef] [PubMed] 
31. Choi, Y.; Lim, S.Y.; Jun, J.Y.; Lee, S.H.; Yoo, S.Y.; Kim, S.; Gwak, A.R.; Kim, J.-C.; Lee, Y.J.; Kim, S.J. The effect of traumatic experiences and psychiatric symptoms on the life satisfaction of North Korean refugees. Psychopathology 2017, 50, 203-210. [CrossRef] [PubMed]

32. Macdonald, D.S. The Koreans: Contemporary Politics and Society; Routledge: London, UK, 2018.

33. Cathcart, A.; Korhonen, P. Death and Transfiguration: The Late Kim Jong-il Aesthetic in North Korean Cultural Production. Popul. Music Soc. 2017, 40, 390-405. [CrossRef]

34. Report on Human Rights Abuses or Censorship in North Korea. Available online: https://www.state.gov/ $\mathrm{j} / \mathrm{drl} / \mathrm{rls} / 266853 . h \mathrm{htm}$ (accessed on 11 January 2017).

35. Yi, S.H. The Social and Psychological Acculturation of North Korean Refugees; SNU Press: Seoul, Korea, 2014.

36. Lee, H.J. The Abuses of Human Rights and Identity Change Processes of Women Defectors from North Korea: Focusing on Married Lives of North Korean Women Defectors in North Korea, China, and South Korea. Ph.D. Thesis, Hanyang University, Seoul, Korea, 2010.

37. Nam, B.; Kim, J.Y.; Ryu, W. Intimate partner violence against women among North Korean refugees: A comparison with South Koreans. J. Interpers. Violence 2017. [CrossRef] [PubMed]

38. Karunakara, U.K.; Neuner, F.; Schauer, M.; Singh, K.; Hill, K.; Elbert, T.; Burnha, G. Traumatic events and symptoms of post-traumatic stress disorder amongst Sudanese nationals, refugees and Ugandans in the west Nile. Afr. Health Sci. 2004, 4, 83-93. [PubMed]

39. Lankov, A. North Korean refugees in Northeast China. Asian Surv. 2004, 44, 856-873. [CrossRef]

40. Lee, H.Y.; Gerber, J. ‘We Just Do What We Think Is Right. We Just Do What We Are Told: 'Perceptions of Crime and Justice of North Korean Defectors. Asia Pac. J. Police Crim. Justice 2009, 7, 21-48.

41. Chan, E.; Schloenhardt, A. North Korean refugees and international refugee law. Int. J. Refug. Law 2007, 19, 215-245. [CrossRef]

42. Lee, Y.; Lee, M.K.; Chun, K.H.; Lee, Y.K.; Yoon, S.J. Trauma experience of North Korean refugees in China. Am. J. Prev. Med. 2001, 20, 225-229. [CrossRef]

43. Kim, H.; Oh, S. The MMPI-2 profile of North Korean female refugees. Korean J. Psychol. Gen. 2010, $29,1-20$.

44. Kim, J.Y.; Choi, J.H.; Ryu, W. Impact of PTSD on North Korean Defector's Social Adjustment in South Korea; Focused on the Moderating Effect of Resilience and Social Interaction. Korean J. Soc. Welf. Stud. 2012, 43, 343-367.

45. Kim, B.; Yoo, S. North Korean Defectors Panel Study (Economic Adaptation, Mental Health Physical Health); North Korean Refugees Foundation: Seoul, Korea, 2010.

46. Carlson, E.B.; Rosser-Hogan, R. Trauma experiences, posttraumatic stress, dissociation, and depression in Cambodian refugees. Am. J. Psychiatry 1991, 148, 1548-1551. [PubMed]

47. Hofmann, S.G.; Litz, B.T.; Weathers, F.W. Social anxiety, depression, and PTSD in Vietnam veterans. J. Anxiety Disord. 2003, 17, 573-582. [CrossRef]

48. Quinn, N. Participatory action research with asylum seekers and refugees experiencing stigma and discrimination: The experience from Scotland. Disabil. Soc. 2014, 29, 58-70. [CrossRef]

49. Masoom, M.R. Social isolation of the stateless and the destitute: A study on the refugee-camp and the sullied slum of Dhaka city. Urban Stud. Res. 2016, 2016, 9017279. [CrossRef]

50. Lindert, J.; von Ehrenstein, O.S.; Priebe, S.; Mielck, A.; Brähler, E. Depression and anxiety in labor migrants and refugees-A systematic review and meta-analysis. Soc. Sci. Med. 2009, 69, 246-257. [CrossRef] [PubMed]

51. Heeren, M.; Wittmann, L.; Ehlert, U.; Schnyder, U.; Maier, T.; Müller, J. Psychopathology and resident status-comparing asylum seekers, refugees, illegal migrants, labor migrants, and residents. Compr. Psychiatry 2014, 55, 818-825. [CrossRef] [PubMed]

52. Harman, R.; Lee, D. The role of shame and self-critical thinking in the development and maintenance of current threat in post-traumatic stress disorder. Clin. Psychol. Psychother. 2010, 17, 13-24. [CrossRef] [PubMed]

53. Cloitre, M.; Miranda, R.; Stovall-McClough, K.C.; Han, H. Beyond PTSD: Emotion regulation and interpersonal problems as predictors of functional impairment in survivors of childhood abuse. Behav. Ther. 2005, 36, 119-124. [CrossRef]

54. Ehring, T.; Quack, D. Emotion regulation difficulties in trauma survivors: The role of trauma type and PTSD symptom severity. Behav. Ther. 2010, 41, 587-598. [CrossRef] [PubMed]

55. Hu, S.H.; Park, E.; Park, J.; Jung, T. Social Adaptation of College Students from North Korea: A Case Study with Focus on Complex-PTSD. Korean J. Stress Res. 2008, 21, 193-202. 
56. Thew, G.R.; Gregory, J.D.; Roberts, K.; Rimes, K.A. Self-critical thinking and overgeneralization in depression and eating disorders: An experimental study. Behav. Cognit. Psychother. 2017, 45, 510-523. [CrossRef] [PubMed]

57. Van der Kolk, B.A. Developmental trauma disorder: Toward a rational diagnosis for children with complex trauma histories. Psychiatr. Ann. 2017, 35, 401-408. [CrossRef]

58. Chang, C.; Kaczkurkin, A.N.; Mclean, C.P.; Foa, E.B. Emotion Regulation Is Associated With PTSD and Depression among Female Adolescent Survivors of Childhood Sexual Abuse. Psychol. Trauma. Theory, Res. Pract. Policy 2017. [CrossRef] [PubMed]

59. Rzeszutek, M.; Oniszczenko, W.; Firlag-Burkacka, E. Social support, stress coping strategies, resilience and posttraumatic growth in a Polish sample of HIV-infected individuals: Results of a 1 year longitudinal study. J. Behav. Med. 2017, 40, 942-954. [CrossRef] [PubMed]

60. Fong, A.J.; Scarapicchia, T.M.; McDonough, M.H.; Wrosch, C.; Sabiston, C.M. Changes in social support predict emotional well-being in breast cancer survivors. Psycho-Oncology 2017, 26, 664-671. [CrossRef] [PubMed]

61. Elzinga, B.M.; Schmahl, C.G.; Vermetten, E.; van Dyck, R.; Bremner, J.D. Higher Cortisol Levels Following Exposure to Traumatic Reminders in Abuse-Related PTSD. Neuropsychopharmacology 2003, 28, 1656-1665. [CrossRef] [PubMed]

62. McQuaid, R.J.; McInnis, O.A.; Paric, A.; Al-Yawer, F.; Matheson, K.; Anisman, H. Relations between plasma oxytocin and cortisol: The stress buffering role of social support. Neurobiol. Stress 2016, 3, 52-60. [CrossRef] [PubMed]

63. Andrews, B.; Brewin, C.R.; Rose, S. Gender, social support, and PTSD in victims of violent crime. J. Trauma. Stress 2003, 16, 421-427. [CrossRef] [PubMed]

64. Stewart, M.; Anderson, J.; Beiser, M.; Mwakarimba, E.; Neufeld, A.; Simich, L.; Spitzer, D. Multicultural meanings of social support among immigrants and refugees. Int. Migr. 2008, 46, 123-159. [CrossRef]

65. Phillips, D.R.; Siu, O.L.; Yeh, A.G.O.; Cheng, K.H.C. Informal social support and older persons' psychological well-being in Hong Kong. J. Cross Cult. Gerontol. 2008, 23, 39-55. [CrossRef] [PubMed]

66. Livingston, G.; Minushkin, S.; Cohn, D. Hispanics and Health Care in the United States: Access, Information and Knowledge; Pew Hispanic Center: Washington, DC, USA, 2008.

67. Hurtado-de-Mendoza, A.; Gonzales, F.A.; Serrano, A.; Kaltman, S. Social isolation and perceived barriers to establishing social networks among Latina immigrants. Am. J. Commun. Psychol. 2014, 53, 73-82. [CrossRef] [PubMed]

68. Boyd, B.A. Examining the relationship between stress and lack of social support in mothers of children with autism. Focus Autism Dev. Disab. 2002, 17, 208-215. [CrossRef]

69. Ullman, S.E.; Filipas, H.H. Correlates of formal and informal support seeking in sexual assault victims. J. Interpers. Violence 2001, 16, 1028-1047. [CrossRef]

70. Lee, Y.H. Changes in the North Korean Economy Reported by North Korean Refugees. North Korean Rev. 2008, 4, 49. [CrossRef]

71. Jeon, W.T. Issues and problems of adaptation of North Korean defectors to South Korean society: An in-depth interview study with 32 defectors. Yonsei Med. J. 2000, 41, 362-371. [CrossRef] [PubMed]

72. Kim, G.C. A study on North Korean Defectors adaptations to local community-focusing on North Korean women. Korean Acad. Qual. Res. Soc. Welf. 2015, 9, 201-225.

73. Ministry of Unification. Nationwide Survey about Settlement of North Korean Refugees in South Korea; Kerea Hana Foundation: Seoul, Korea, 2017.

74. Ministry of Unification. Nationwide Survey about Social Integration Survey for North Korean Refugees; Kerea Hana Foundation: Seoul, Korea, 2017.

75. Sohn, H.M. The Korean Language; Cambridge University Press: Cambridge, UK, 2001.

76. Chung, J.K.; Cho, J.A. Issues in the Integration Education for North Korean Refugees and South Korean Hosts. Korean Psychol. Assoc. 2008, 14, 487-518.

77. Yang, H.R.; Ko, Y.J.; Kim, Y.S.; Park, Y.M.; Lee, H.R. School Life of North Korean Defectors Born in the Third Country: Qualitative Case Study. Korean Acad. Soc. Welf. 2017, 39, 205-229. [CrossRef]

78. Kim, M.R. The effect of the adjustment stress and the social support on the depressive symptoms of the North Korean defectors. Korean Acad. Soc. Welf. 2005, 57, 193-217. 
79. Park, K.; Cho, Y.; Yoon, I.J. Social inclusion and length of stay as determinants of health among North Korean refugees in South Korea. Int. J. Public Health. 2009, 54, 175-182. [CrossRef] [PubMed]

80. Bidet, E. Social capital and work integration of migrants: The case of North Korean defectors in South Korea. Asian Perspect. 2009, 33, 151-179.

81. Faul, F.; Erdfelder, E.; Lang, A.G.; Buchner, A.G. G*Power 3: A flexible statistical power analysis program for the social, behavioral, and biomedical sciences. Behav. Res. Methods 2007, 39, 175-191. [CrossRef] [PubMed]

82. Cohen, J. Statistical power analysis. Curr. Dir. Psychol. Sci. 1992, 1, 98-101. [CrossRef]

83. Lee, K.S. The Relationship among Leisure Sports participation, Social Support, Loneliness and Social Network of the Elderly. Ph.D. Thesis, Myung-Ji Universsity, Seoul, Korea, 2005.

84. Russell, D.; Peplau, L.A.; Fergusson, M.L. Developing a measure of loneliness. J. Personal. Assess. 1978, 42, 290-294. [CrossRef] [PubMed]

85. Jeon, W.T.; Yoon, D.R.; Um, J.S. Survey Results of Adaptation and Life of North Korean Defectors in South Korea, 2001. Korean Unific. Stud. 2003, 7, 155-208.

86. Kim, S.; Choi, B. The Effectiveness of PTSD Program of North Korean Refugees: For North Korean Female Refugees. Korean J. Woman Psychol. 2013, 18, 533-548.

87. Kim, J. Y.; Ryu, W. A Study on Cycle of Child Abuse among North Korean Refugee Women: Focused on Aggravating Effects of Spouse Abuse. Korean Fam. Welf. Assoc. 2016, 52, 375-399.

88. O'Donnell, D.A.; Roberts, W.C. Experiences of violence, perceptions of neighborhood, and psychosocial adjustment among West African refugee youth. Int. Perspect. Psychol. Res. Pract. Consult. 2015, 4, 1-18. [CrossRef]

89. Bauer, J.L. Desiring Place: Iranian" refugee" women and the cultural politics of self and community in the Diaspora. Comp. Stud. South Asia Afr. Middle East 2000, 20, 180-199. [CrossRef]

90. Lie, B.A. 3-year follow-up study of psychosocial functioning and general symptoms in settled refugees. Acta Psychiatr. Scand. 2002, 106, 415-425. [CrossRef] [PubMed]

91. Rothbaum, B.O.; Kearns, M.C.; Reiser, M.E.; Davis, M.J.S.; Kerley, M.K.A.; Rothbaum, M.A.O.; Mercer, K.B.; Price, M.; Houry, D.; Ressler, K.J. Early intervention following trauma may mitigate genetic risk for PTSD in civilians: A pilot prospective emergency department study. J. Clin. Psychiatry 2014, 75, 1380. [CrossRef] [PubMed]

92. Boateng, A. Survival voices: Social capital and the well-being of Liberian refugee women in Ghana. J. Immigr. Refug. Stud. 2010, 8, 386-408. [CrossRef]

93. Lee, S.Y.; Shin, H.K. In Plans to Enhance the Capability of the Security Police to Prevent Social Deviance of North Korean Defectors, 2013. Korean Assoc. Public Secur. Adm. 2013, 9, 45-66.

94. Halbesleben, J.R. Sources of social support and burnout: A meta-analytic test of the conservation of resources model. J. Appl. Psychol. 2006, 91, 1134. [CrossRef] [PubMed]

95. Thoits, P.A. Stress, coping, and social support processes: Where are we? What next? J. Health Soc. Behav. 1995. [CrossRef]

96. Kim, H.S.; Sherman, D.K.; Taylor, S.E. Culture and social support. Am. Psychol. 2008, 63, 518. [CrossRef] [PubMed]

97. Crush, J.; Ramachandran, S. Xenophobia, International Migration and Human Development; No. HDRP-2009-47; Human Development Report Office (HDRO), United Nations Development Programme (UNDP). Revised September 2009. Available online: https://ideas.repec.org/p/hdr/papers/hdrp-2009-47.html (accessed on 1 September 2009).

98. Sow, P.; Adaawen, S.A.; Scheffran, J. Migration, social demands and environmental change amongst the Frafra of Northern Ghana and the Biali in Northern Benin. Sustainability 2014, 6, 375-398. [CrossRef]

99. Pachocka, M. The European Union and international migration in the early 21st century: Facing the migrant and refugee crisis in Europe. In Re-thinking EU Education on and Research for Smart and Inclusive Growth (EuInteg); PECSA: Warsaw, Poland, 2015; pp. 531-557. Available online: https://depot.ceon.pl/ handle/123456789/10269 (accessed on 17 April 2018). 
100. Castles, S. Development and migration-Migration and development: What comes first? Global perspective and African experiences. Theoria 2009, 56, 1-31. [CrossRef]

101. Scheffran, J.; Marmer, E.; Sow, P. Migration as a contribution to resilience and innovation in climate adaptation: Social networks and co-development in Northwest Africa. Appl. Geogr. 2012, 33, 119-127. [CrossRef] 